\title{
NUMERICAL ESTIMATION \\ OF THE PILE TOE AND SHAFT UNIT RESISTANCES DURING THE INSTALLATION PROCESS IN SANDS
}

\author{
JAKUB KONKOL \\ Department of Geotechnics, Geology and Marine Civil Engineering, Faculty of Civil and Environmental Engineering, \\ Gdańsk University of Technology (GUT), Gdańsk, Poland, \\ e-mail: vinkerlid@gmail.com
}

\begin{abstract}
Numerical simulations of a pile jacking were carried out. A Coupled Eulerian-Lagrangian (CEL) formulation was used to treat with large deformation problems. An Abaqus, a commercial Finite Element Method software suit, was used as a computing environment. The Mohr-Coulomb constitutive model was applied and the Coulomb model of friction was used to describe pile-soil interaction. Calculations were made for three different pile diameters. Toe and shaft unit resistances versus depth for each pile were investigated and plotted. CPT-based solutions were compared with the results of numerical simulations.
\end{abstract}

Key words: Coupled Eulerian-Lagrangian (CEL), Abaqus, pile toe resistance, pile shaft resistance

\section{INTRODUCTION}

The rapid development of numerical methods in the last few years has opened up new possibilities in geotechnical modelling. A big amount of these methods are dedicated to face large deformation problems. The most popular are Arbitrary Lagrangian-Eulerian formulation (ALE) [1], Coupled Eulerian-Lagrangian formulation (CEL) [2], Smoothed Particle Hydrodynamics method (SPH) [3], Material Point Method (MPM) [4], [5] and Particle Finite Element Method (PFEM) [6]. Three of these methods: ALE, CEL and SHP are part of Abaqus software suit, but the CEL is the most widely used. Application of a CEL formulation in geotechnical modelling was shown by Qiu et al. [7]. A pile jacking is a typical large deformation problem. Pucker and Grabe [8] have done a simulation of an installation of a full displacement pile and Qiu et al. [9] have performed a pile jacking simulation. In this paper, pile jacking simulations have been carried out to obtain unit resistances of the toe and the shaft of the pile. The simulations were preceded by benchmark tests to get accurate input quantities, such as mesh size and jacking velocity. Afterwards, the specific numerical model was developed. The results of numerical investigations were compared and related to the CPT-based solutions for unit toe and shaft resistances.

\section{SOIL PARAMETERS}

The CPT and DMT in-situ measurements in loose/medium dense sands were performed. The results of CPT and DMT probing are graphically presented in Fig. 1. The water table level was high enough for the assumption that it is equal to the ground surface. For calculation purposes the average value of geotechnical parameters was determined. The averaging was done to the depths of $12.0 \mathrm{~m}$. The soil was modelled as an elastoplastic body with Mohr-Coulomb failure criterion. The material parameters used in numerical model are listed in Table 1 . In the analysis, the drained conditions were assumed due to high permeability of sands and standard insertion velocity of the CPT cone. The total soil unit weight based on CPT probing was calculated using the following equation [10]

$$
\frac{\gamma_{\text {tot }}}{\gamma_{\text {water }}}=0.27\left(\log R_{F}\right)+0.36\left[\log \left(q_{t} / p_{a}\right)\right]+1.236
$$

where $\gamma_{\text {tot }}-$ total soil unit weight $\left[\mathrm{N} / \mathrm{m}^{3}\right], \gamma_{\text {water }}-$ water unit weight $\left[\mathrm{N} / \mathrm{m}^{3}\right], R_{F}-$ friction ratio $[-], q_{t}-$ tip resistance $[\mathrm{kPa}], p_{a}-$ atmospheric pressure $[\mathrm{kPa}]$.

Thus, the submerged soil density will be given as

$$
\rho^{\prime}=\frac{\gamma_{\text {tot }}-\gamma_{\text {water }}}{g}
$$


where $\rho^{\prime}-$ submerged soil density $\left[\mathrm{kg} / \mathrm{m}^{3}\right], \gamma_{\text {tot }}-$ total soil unit weight $\left[\mathrm{N} / \mathrm{m}^{3}\right], \gamma_{\text {water }}-$ water unit weight $\left[\mathrm{N} / \mathrm{m}^{3}\right], g-$ acceleration due to gravity $\left[\mathrm{m} / \mathrm{s}^{2}\right]$.

Young's modulus was estimated on DMT probing and it is given by the equation [11]

$$
E=0.8 M_{D M T}
$$

where $E$ - Young's modulus [MPa], $M_{\mathrm{DMT}}-$ Constrained modulus [MPa].

Equation (3) enforces Poisson's ratio in the range of $0.25-0.3$. Hence, Poisson's ratio of 0.27 was stated. The effective angle of friction based on DMT probing was calculated using the equation [11]

$$
\Phi^{\prime}=\Phi_{\text {safe, } \mathrm{DMT}}=28^{\circ}+14.6^{\circ} \cdot \log K_{D}-2.1^{\circ} \cdot \log ^{2} K_{D}
$$

where $\Phi^{\prime}$ - effective angle of internal friction $\left[{ }^{\circ}\right]$, $\Phi_{\text {safe,DMT }}$ - lower bound of effective angle of internal friction $\left[^{\circ}\right], K_{D}-$ horizontal stress index [-].
Lateral earth at rest pressure coefficient was calculated using Jaky correlation. Effective cohesion of $1 \mathrm{kPa}$ was assumed to avoid numerical complications. In pile jacking simulation dilatancy should be taken into account. Angle of dilation can be estimated using the following equations [12]:

$$
\begin{gathered}
\sin \psi=\frac{0.3 I_{R}}{2+0.3 I_{R}}, \\
I_{R}=I_{D}(\mathrm{Q}-\ln p)-\mathrm{R}
\end{gathered}
$$

where $\psi$ - dilation angle $\left[{ }^{\circ}\right], I_{R}$ - relative dilatancy index $[-], I_{D}-$ relative density $[-], p$ - effective mean stress [kPa], Q, R - constants.

$\mathrm{Q}=10$ and $\mathrm{R}=1$ give a good fit for quartz sands [12]. The effective mean stress of $300 \mathrm{kPa}$ was assumed for calculations. This is an average value from literature data [13]. The average relative density of 0.53 was estimated using correlations obtained from a) TIP RESISTANCE [kPa]

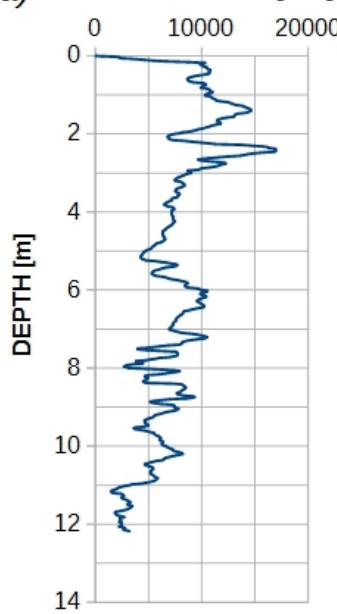

SLEEVE FRICTION [kPa]

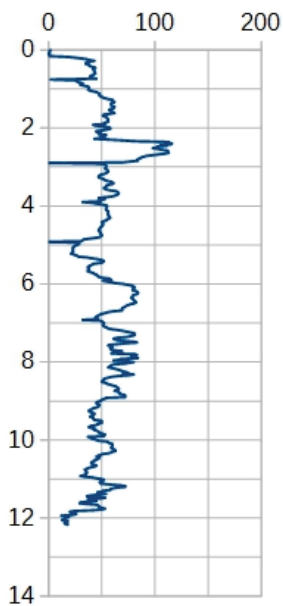

FRICTION RATIO [\%]

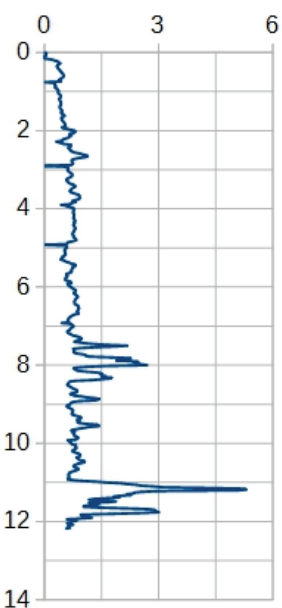

b)
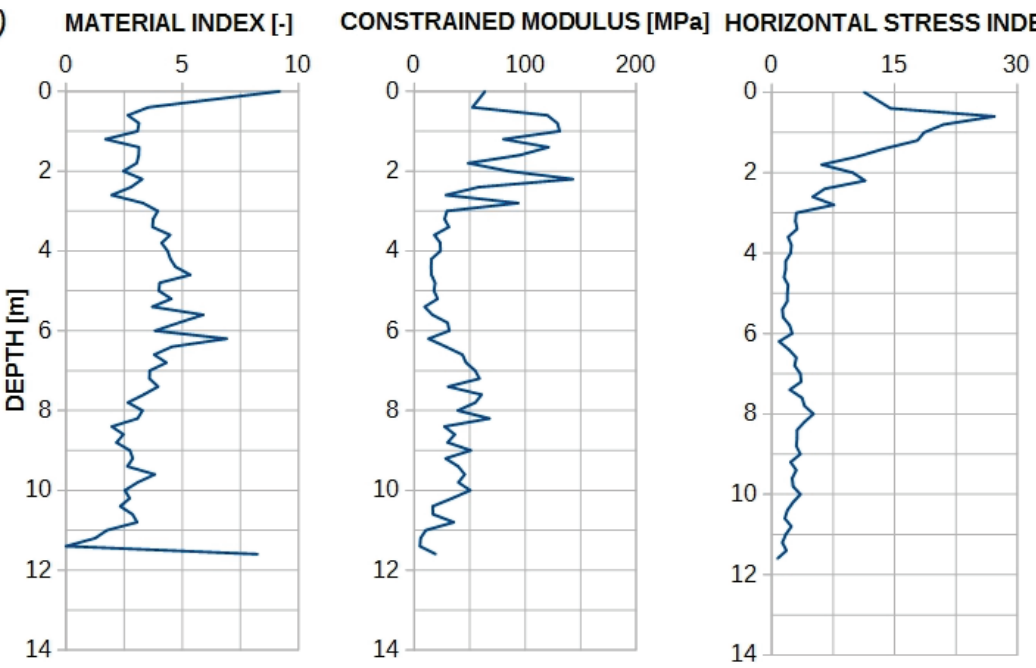

Fig. 1. In-situ measurements probing graphs: (a) CPT, (b) DMT 
Table 1. Material parameters for a numerical model

\begin{tabular}{|c|c|c|c|c|c|c|c|}
\hline Parameter & $\begin{array}{c}\text { Submerged } \\
\text { soil density } \\
\rho^{\prime}\left[\mathrm{kg} / \mathrm{m}^{3}\right]\end{array}$ & $\begin{array}{c}\text { Young } \\
\text { Modulus } \\
E[\mathrm{MPa}]\end{array}$ & $\begin{array}{c}\text { Poisson's } \\
\text { ratio } \\
v[-]\end{array}$ & $\begin{array}{c}\text { Effective } \\
\text { friction angle } \\
\Phi^{\prime}\left[{ }^{\circ}\right]\end{array}$ & $\begin{array}{c}\text { Dilation } \\
\text { angle } \\
\psi\left[{ }^{\circ}\right]\end{array}$ & $\begin{array}{c}\text { Effective } \\
\text { cohesion } \\
c^{\prime}[\mathrm{kPa}]\end{array}$ & $\begin{array}{c}\text { Earth at } \\
\text { rest pressure } \\
\text { coefficient } \\
K_{0}[-]\end{array}$ \\
\hline Value & 877 & 35.7 & 0.27 & 35.2 & 9.0 & 1.0 & 0.424 \\
\hline
\end{tabular}

calibration chamber tests [14]. Hence, an approximate dilation angle of $9^{\circ}$ was calculated from equations (5) and (6).

\section{DEVELOPING THE NUMERICAL MODEL}

\subsection{COUPLED EULERIAN-LAGRANGIAN (CEL) FORMULATION}

In traditional Finite Element Methods (FEM) a mesh distortion usually appears where large deformations occur. This is the biggest problem in FEM modelling. The CEL method combines the best features of the Lagrangian and the Eulerian formulations [2] to avoid the mesh distortion problem. In this kind of simulation each domain in discretized in Eulerian or Lagrangian manner. Domain, which is modelled in Eulerian mode, can be partially or fully filled with the material. In this domain, a body may be located, which is discertized with Lagrangian mesh. A general contact algorithm defines contact properties between Lagrangian and Eulerian sections and enforces contact when Lagrangian element encounters Eulerian element filled with material. Thus, CEL formulation enables modelling large deformations without taking care of the mesh distortion. However, CEL method, as it is implemented in Abaqus, requires 3D finite elements [15]. Hence, a plane problem needs to be considered in $3 \mathrm{D}$ manner, where the third dimension is usually the depth of Eulerian finite element.

\subsection{CONTACT FORMULATION}

Interaction between pile and soil is modelled by a general contact algorithm, which uses a penalty contact method. This method searches for small nodal penetrations between surfaces where contact occurs. Contact force and penetration distance are related to penalty stiffness, which is chosen automatically by Abaqus software to get the insignificant penetration and a minimal effect on time integration [15]. Pilesoil interaction is modelled as a tangential behaviour.
The Coulomb friction model is used with a coefficient of friction $\mu$ defined as follows

$$
\mu=\tan (\delta)=\tan \left(\frac{1}{3} \Phi^{\prime}\right)
$$

where $\mu$-Coulomb's coefficient of friction [-], $\Phi^{\prime}-$ angle of internal friction $\left[{ }^{\circ}\right], \delta$ - angle of friction $\left[{ }^{\circ}\right]$.

Substituting internal friction angle of 35.2 degrees, as presented in Table 1, the coefficient of friction returns value of 0.2077

\subsection{BENCHMARK TESTS}

Benchmarks are very helpful to define the reliability of numerical simulation due to different variables. A series of benchmark tests were performed to measure the influence of mesh size and jacking velocity on the numerical tests results. The benchmarks undertook a strip foundation problem. A strip of $1.0 \mathrm{~m}$ in width was pressed with a constant velocity and bearing capacity was calculated. The elasto-plastic material model with parameters as presented in Table 1 was used. The soil was considered as weightless. This additional assumption has to be made according to Prandtl analytical solution, which is given as [16]

$$
q_{\mathrm{ult}}=c^{\prime} \cdot \sin \Phi^{\prime}\left[\frac{1+\sin \Phi^{\prime}}{1-\sin \Phi^{\prime}} \exp \left(\pi \cdot \tan \Phi^{\prime}\right)-1\right]
$$

where $q_{\text {ult }}-$ ultimate bearing capacity of a strip footing $[\mathrm{kPa}], c^{\prime}-$ internal cohesion $[\mathrm{kPa}], \Phi^{\prime}-$ angle of internal friction $\left[{ }^{\circ}\right]$.

The error of the numerical tests against the analytical solution was calculated. The most appropriate mesh for Eulerian domain is a perfectly cubic one [15], but, it can be seen that a gently biased mesh can be as effective as a perfectly cubic one. However, this is due to dimension of $8 \mathrm{~cm}$ of the shorter edge of an element and the whole mesh design, where the finer mesh is placed in the center of domain. Three pressing velocities of 5,25 and $50 \mathrm{~cm} / \mathrm{s}$ were tested. The velocity of $25 \mathrm{~cm} / \mathrm{s}$ is a good one for further calculations because of restrained solution noise. Also, the strip mesh size does not affect reliability of simulation so 
Table 2. Benchmark tests for the bearing capacity of a strip footing

\begin{tabular}{|c|c|c|c|c|c|c|}
\hline \multirow[b]{2}{*}{$\begin{array}{l}\text { Test } \\
\text { No. }\end{array}$} & \multicolumn{2}{|c|}{ Soil domain (Eulerian) } & \multirow[b]{2}{*}{$\begin{array}{c}\text { Pressing } \\
\text { velocity } \\
{[\mathrm{cm} / \mathrm{s}]}\end{array}$} & \multicolumn{2}{|c|}{ Bearing capacity $[\mathrm{kPa}]$} & \multirow[b]{2}{*}{$\begin{array}{c}\text { Error } \\
{[\%]}\end{array}$} \\
\hline & \begin{tabular}{|c|} 
Finite \\
element depth \\
{$[\mathrm{cm}]$}
\end{tabular} & $\begin{array}{c}\text { Mesh plane } \\
\text { dimensions } \\
{[\mathrm{cm}]}\end{array}$ & & $\begin{array}{l}\text { Numerical } \\
\text { solution }\end{array}$ & $\begin{array}{l}\text { Analytical } \\
\text { solution }\end{array}$ & \\
\hline 1 & 20 & $20 \times 20$ & 5 & 51.486 & \multirow{5}{*}{46.974} & +9.61 \\
\hline 2 & 10 & $10 \times 10$ & 5 & 44.774 & & -4.68 \\
\hline 3 & 10 & $10 \times 10$ & 25 & 47.905 & & +2.66 \\
\hline 4 & 10 & $10 \times 10$ & 50 & 55.155 & & +17.42 \\
\hline 5 & 10 & $\begin{array}{c}\text { Biased mesh } \\
8 \text { to } 12 \times 8 \text { to } 12\end{array}$ & 25 & 44.032 & & -6.26 \\
\hline
\end{tabular}

much. The total error based on benchmark tests is $6.28 \%$. For pile jacking numerical calculations, it could be a little higher, but should not exceed $10 \%$.

\subsection{PILE JACKING TEST - MODEL GEOMETRY}

Benchmark tests are very useful to set the starting parameters for numerical model of a pile jacking. Based on results presented in the previous section, the geometry, boundary conditions and loading for a pile driving process were determined. The biased mesh was applied with element dimensions of (8-10) $\times(8-10) \times 10 \mathrm{~cm}$. Jacking velocity was set as $25 \mathrm{~cm} / \mathrm{s}$ with a smooth step amplitude, where velocity has increased from 0 to $25 \mathrm{~cm} / \mathrm{s}$ within the time of $1 \mathrm{~s}$. This smooth step was used to reduce the solution

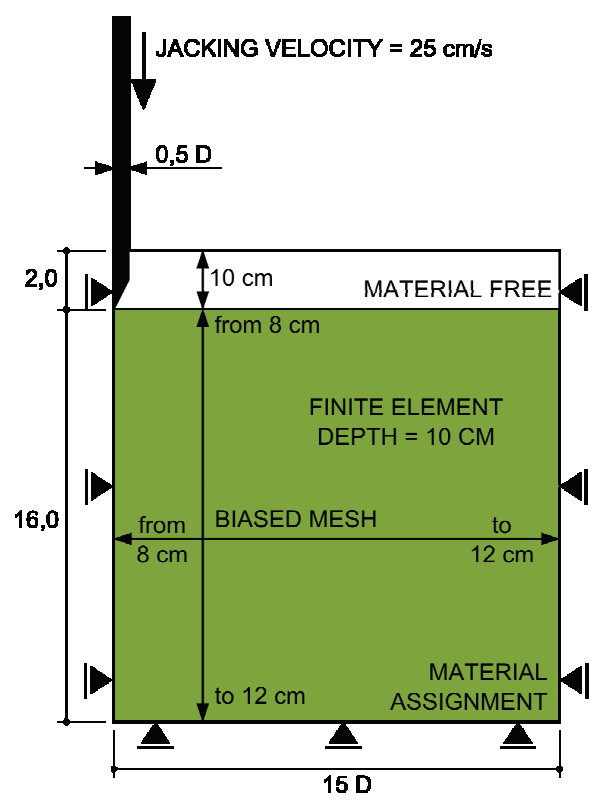

TESTED CONES:
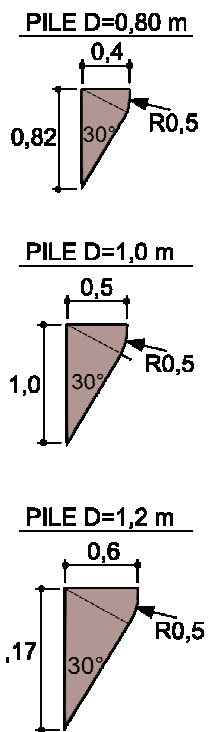

Fig. 2. Geometry and boundary conditions for pile jacking simulation noise [15]. The geometry of a numerical model is illustrated in Fig. 2. The benchmarks have answered a lot of basic questions, but they were useless as regards the influence of a boundary effect. For the estimation of required soil domain width, the research papers were used. According to them, a domain width should has dimension of 10D to 30D [7]-[9], where $\mathrm{D}$ is a pile diameter. In present analysis, the width of the soil domain was set to be equal to $15 \mathrm{D}$. The symmetry advantage was also applied. The three piles were tested with diameters of $0.8 ; 1.0$ and $1.2 \mathrm{~m}$. The tips of the piles were designed to get maximum similarity with the CPT cone. They are presented in Fig. 3. The rounding between the cone of the pile and the peripheral was designed to obtain better material flow around the pile. The approximated mesh size for a pile was set to $20 \mathrm{~cm}, 25 \mathrm{~cm}$ and $30 \mathrm{~cm}$ for diameters of $0.8 ; 1.0$ and $1.2 \mathrm{~m}$, respectively. The initial pre-

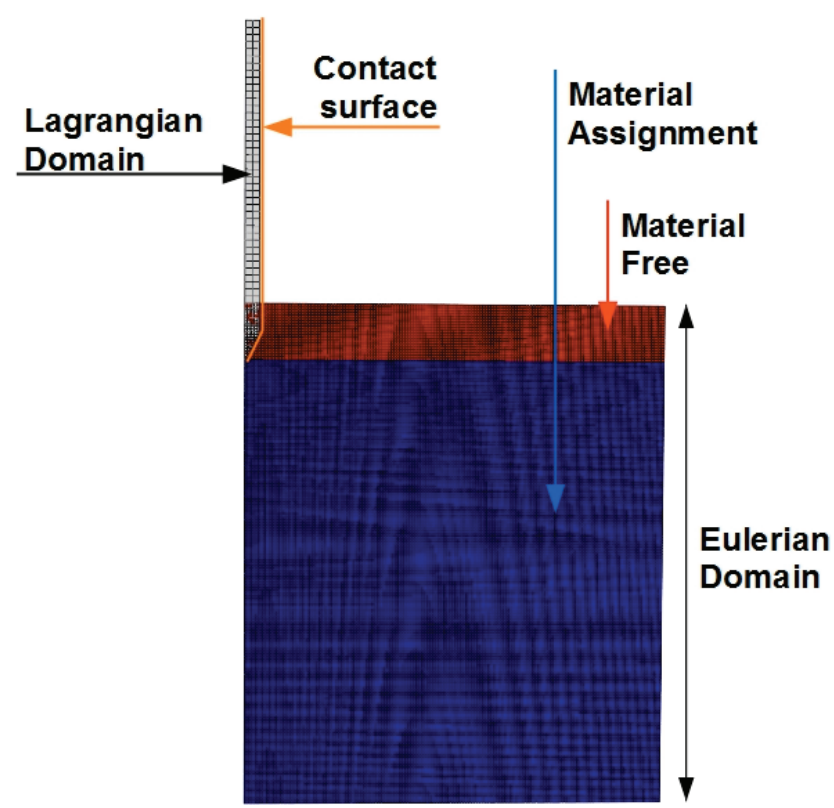

Fig. 3. Lagrangian and Eulerian domains for pile jacking simulation 
defined stress field was applied as geostatic stress with lateral stress coefficient of 0.424 . The material parameters presented in Table 1 were used. The pile was modelled as perfectly elastic body with Young's modulus of $17 \mathrm{GPa}$, Poisson's ratio of 0.12 and density of $2300 \mathrm{~kg} / \mathrm{m}^{3}$. These parameters give high stiffness of a pile in comparison with the soil structure. The simulation of a jacking process was carried out to the depth of 10 meters. The Eulerian and Lagrangian finite element approaches with pile-soil contact area in numerical model are shown in Fig. 4. Pile toe and shaft resistances during jacking have been investigated.

\subsection{RESULTS OF A SIMULATIONS}

As a result of calculations, the total force acting on the surface is provided. Although the Abaqus offers a total contact area, the values are not excessively
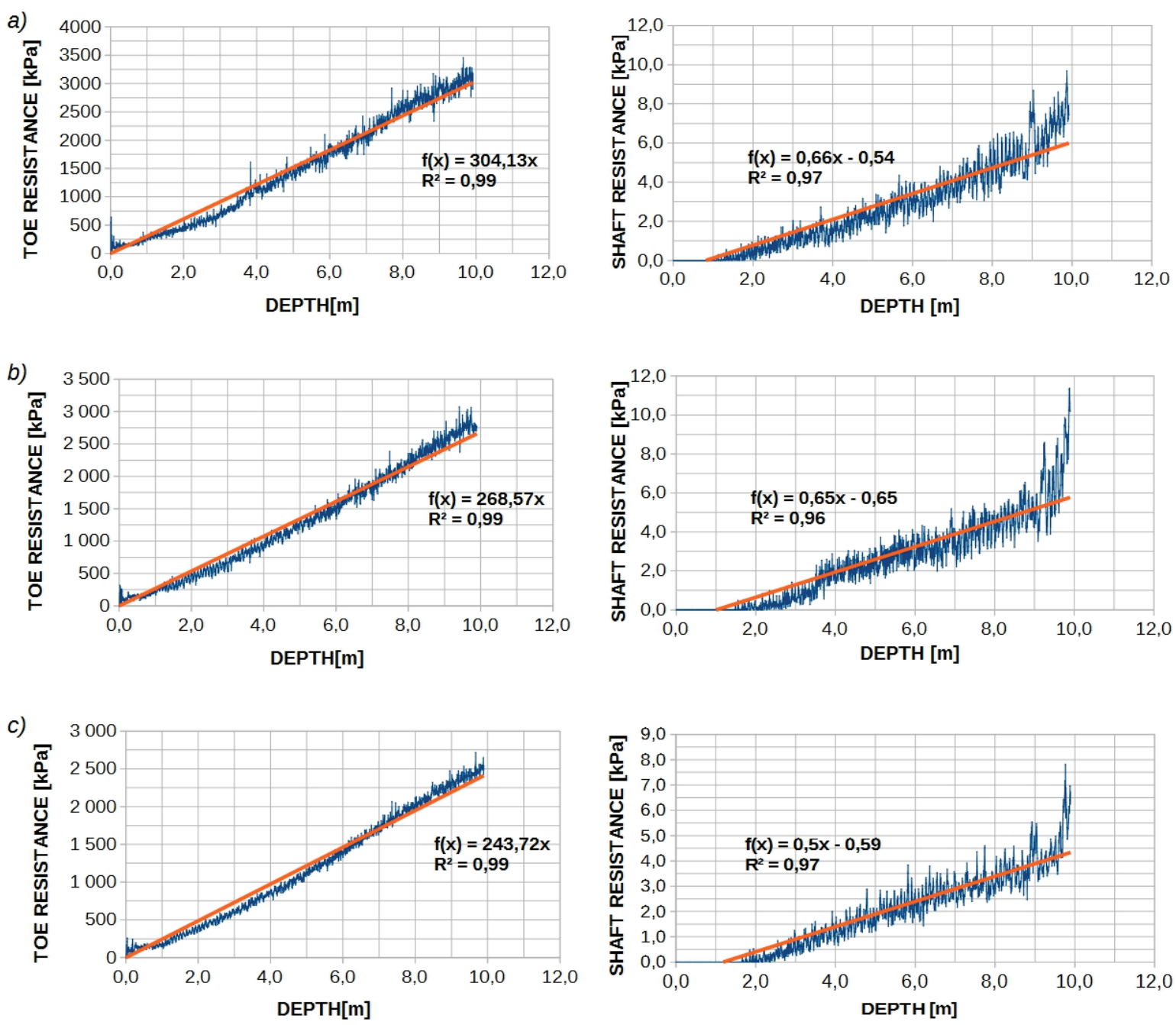

Fig. 4. Pile toe and shaft unit resistances for:

(a) $0.8 \mathrm{~m}$ diameter pile, (b) $1.0 \mathrm{~m}$ diameter pile, (c) $1.2 \mathrm{~m}$ diameter pile

precise and should not be used for stress calculations [15]. Therefore, total contact area was calculated using depth-time relationship and a known geometry of a pile. The unit pile toe and shaft resistances for three different pile diameters are plotted in Fig. 4. As can be seen, the resistances can be approximated by a linear function. Coefficient of determination reaches high values ranging from 0.96 to 0.99 with a low level of noise. However, the reliability of $10 \%$ in pile jacking solutions can be expected due to benchmark test results.

The analysis performed showed that boundary effects do not affect simulation so much. At the vertical border no plastic strains were observed, so the influence of boundary effects is probably low in this region. However, at the horizontal border an accumulation of a plastic strain is detected. This process started at $8.5 \mathrm{~m}$ and lasted to the end of jacking when $10 \mathrm{~m}$ depth was reached. In that range boundary effects surely occur. The accumulation of plastic strains at the
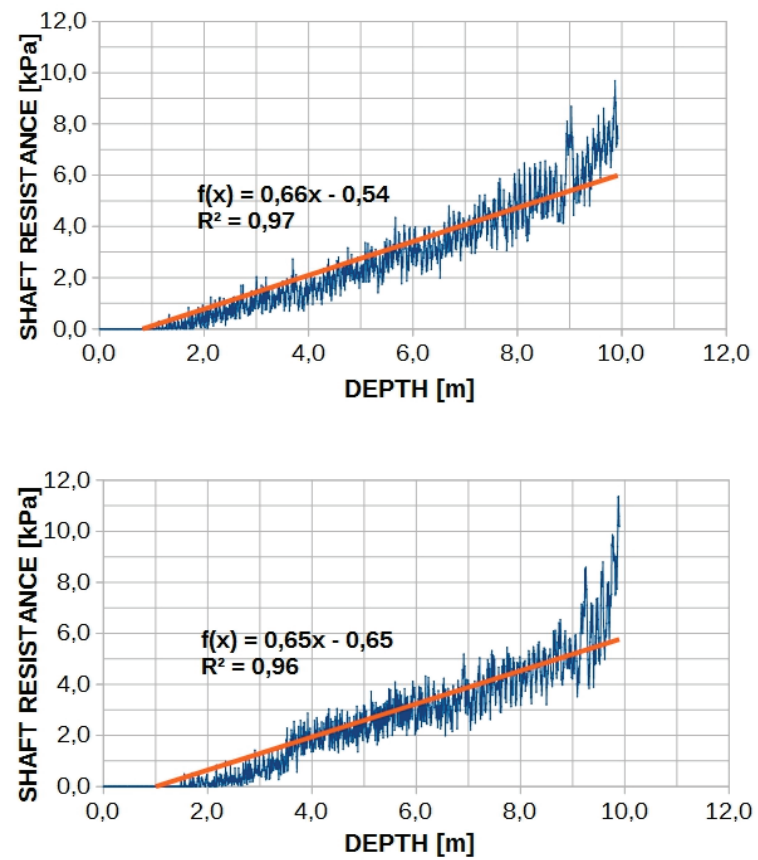
depth of $10 \mathrm{~m}$ is presented in Fig. 5. The influence of boundary effects can be seen also in the shaft unit resistance, where sudden increase of resistance along the last meter of jacking can be observed.

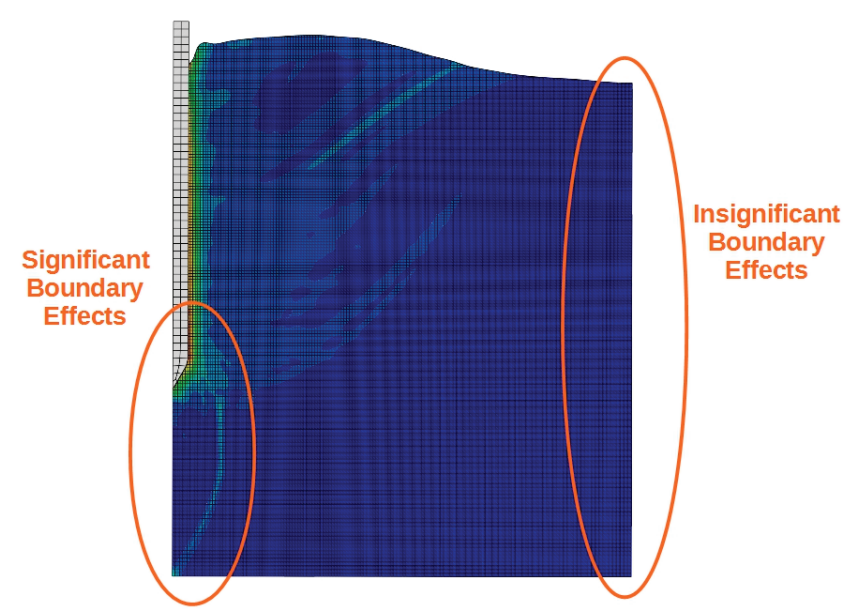

Fig. 5. A maximum principal plastic strain at a depth of $10.0 \mathrm{~m}$

\section{VALIDATION OF THE NUMERICAL MODEL}

The validation of the numerical model may be difficult for two main reasons. Firstly, a simple constitutive model was used. This entailed average material parameters from CPT and DMT probing, as was explained in Section 2. To get reliable data for comparison purposes, some range of the depth has to be stated. The distribution of strength parameters with depth is presented in Fig. 6. As can be seen, only depth range from 7 to 10 meters is suitable for comparison. Due to boundary effects this range should be limited to a depth of 8.5 meters, so the total representative comparison range is form 7.0 to 8.5 meters in depth. Secondly, a problem with estimating values of pile toe and shaft resistances based on CPT measurements occurs. The pile toe resistance is reduced to cone resistance due to scale effects [17]. Pile toe resistance based on CPT probing is usually given as [17]

$$
\begin{gathered}
q_{b}=q_{c}\left[1-0.5 \log \left(D / D_{\mathrm{CPT}}\right)\right] \text { for } D \leq 0.9 \mathrm{~m} \\
q_{b}=0.3 q_{c} \text { for } D>0.9 \mathrm{~m}
\end{gathered}
$$

where $q_{b}$ - pile toe resistance $[\mathrm{kPa}], q_{c}-$ cone resistance $[\mathrm{kPa}], D-$ pile diameter $[\mathrm{m}], D_{\mathrm{CPT}}-\mathrm{CPT}$ cone diameter $[\mathrm{m}]$.

A CPT tip resistance was averaged for depths of 7 to 8.5 meters. A pile shaft resistance can be defined using a sleeve friction or cone resistance and an appropriate coefficient [18]. Here, the pile shaft resistance was calculated using the equation proposed in LCPC method [18]

$$
q_{s}=\frac{q_{c}}{\psi_{2}}
$$

where $q_{s}$ - pile shaft resistance $[\mathrm{kPa}], q_{c}-\mathrm{CPT}$ tip resistance $[\mathrm{kPa}], \psi_{2}$ - coefficient of shaft capacity [-]. For medium dense sands $\psi_{2}=200$ [18].
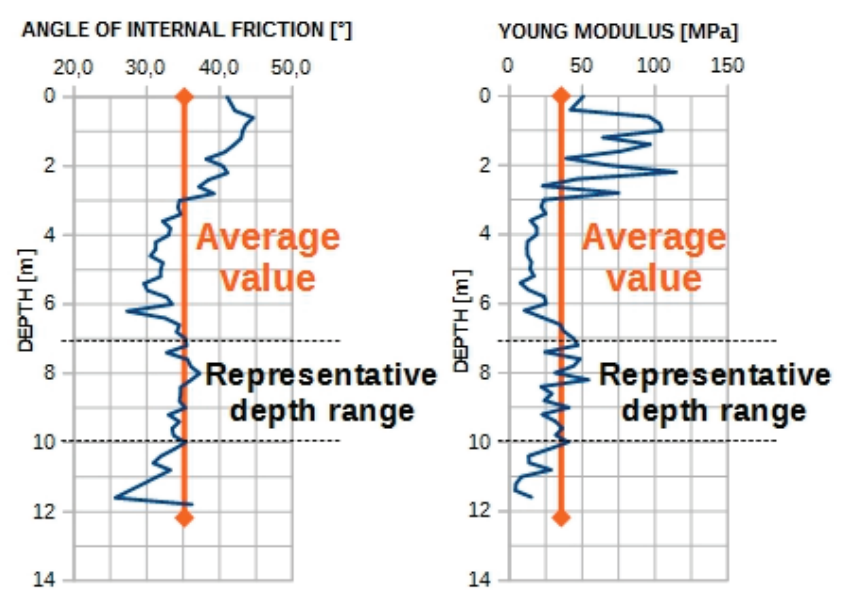

Fig. 6. Representative depth range due to strength parameters

Values of the shaft and the toe resistances were calculated from equations (9), (10), (11) and they were compared with the values obtained from numerical simulations. A full comparison is summarized in Table 3. The analysis of the deviations shows that performance of a numerical experiment provided acceptable solution of the pile toe resistance. Moreover, the calculated deviation is close to the error of $10 \%$, which was the estimate based of benchmark tests for the pile jacking simulation. However, shaft resistances for all testing diameters were significantly underestimated. This is probably due to the low value of the interface friction angle. In this analysis, the interface friction angle of $0,333 \Phi^{\prime}$ was taken. In other research studies, the friction angle is usually determined as $0.7-0,9 \Phi^{\prime}$ [19]. Another question is a difference in numerical solution of toe resistances for different pile diameters. The Mohr-Coulomb constitutive law was applied and the same soil domain width of $15 \mathrm{D}$ was used, so the toe resistances should reach similar values for different piles. As can be seen in Table 3 and in the graphs of Fig. 5, this has not happened. This is probably due to the same soil domain mesh size for all the cases and the same vertical dimension of soil domain, see Fig. 3. Because of the domain mesh size, the results for 
Table 3. Numerical solution versus CPT-based solution for 7-8.5 meters penetration depth

\begin{tabular}{|c|c|c|c|c|c|c|}
\hline \multirow{2}{*}{$\begin{array}{c}\text { Pile } \\
\text { diameter } \\
{[\mathrm{m}]}\end{array}$} & \multicolumn{2}{|c|}{ Numerical solution } & \multicolumn{2}{c|}{ CPT-based solution } & \multicolumn{2}{c|}{$\begin{array}{c}\text { Deviation from CPT-based } \\
\text { solution [\%] }\end{array}$} \\
\cline { 2 - 7 } & $\begin{array}{c}\text { Toe } \\
\text { resistance } \\
{[\mathrm{kPa}]}\end{array}$ & $\begin{array}{c}\text { Shaft } \\
\text { resistance } \\
{[\mathrm{kPa}]}\end{array}$ & $\begin{array}{c}\text { Toe } \\
\text { resistance } \\
{[\mathrm{kPa}]}\end{array}$ & $\begin{array}{c}\text { Shaft } \\
\text { resistance } \\
{[\mathrm{kPa}]}\end{array}$ & $\begin{array}{c}\text { Toe } \\
\text { resistance }\end{array}$ & $\begin{array}{c}\text { Shaft } \\
\text { resistance }\end{array}$ \\
\hline 0.8 & 2485.7 & 5.43 & 2128.0 & 32.58 & +16.81 & -85.93 \\
\hline 1.0 & 2115.9 & 5.01 & 1954.7 & 32.58 & +8.25 & -87.27 \\
\hline 1.2 & 1994.4 & 3.67 & 1954.7 & 32.58 & -0.53 & -90.31 \\
\hline
\end{tabular}

$0.8 \mathrm{~m}$ pile diameter can be slightly overestimated. For a $1.2 \mathrm{~m}$ pile, the vertical domain dimension may play a key role, because it is relatively lower than for $0.8 \mathrm{~m}$ and $1.0 \mathrm{~m}$ piles, so the toe resistance can be underestimated. The same features affect shaft resistance. Because of the much greater noise in relation to the toe resistance, the differences in results for shaft resistances are more difficult to analyse and to compare. Hence, the numerical solution should be treated with great care.

\section{CONCLUSIONS}

The numerical simulations performed have proved that CEL formulation is an effective tool to deal with large deformation problem like pile jacking. Combining Eulerian and Lagrangian features provides a satisfactory estimation of soil response due to the pile jacking. The exclusion of the mesh distortions and hourglass effect in CEL modelling as well as application of general contact algorithm lead to significant improvement in the field of numerical methods. However, the reliability of results depends on many things. The most important is the soil domain mesh size, but the input conditions like jacking velocity and mesh size of pile have a significant influence on the numerical noise. During pile jacking tests the influence of boundary conditions has appeared. Thus, a larger amount of tests should be undertaken in this direction. Further, the highest value of friction coefficient for the pile shaft seems to be more appropriate in terms of true interaction behaviour. The Mohr-Coulomb constitutive law and Coulomb law of friction give acceptable estimation of the pile toe resistance. Other constitutive laws, more suitable for large deformation problems, should be tested as well. Discussion of the results has shown that solution can be ambiguous in interpretation and should be considered with caution.

\section{ACKNOWLEDGEMENTS}

The author would like to thank Dr. Lech Bałachowski for providing CPT and DMT in-situ measurements. The calculations were carried out at the Academic Computer Centre in Gdańsk (CI TASK).

\section{REFERENCES}

[1] Donea J., Huerta A., Ponthot J.P., Rodríguez-Ferran A., Arbitrary Lagrangian-Eulerian methods, Encyclopedia of Computational Mechanics, 2004, DOI: 10.1002/ 0470091355.ecm009.

[2] NoH W.F., CEL: a time-dependent, two-space-dimensional, coupled Eulerian-Lagrangian code, [in:] B. Adler, S. Fernbach, M. Rotenberg (eds.), Methods in Computional Physics, Volume 3. Fundamental Methods in Hydrodynamics, AcademicPress, New York, 1964, 117-179.

[3] Gingold R.A., Monaghan J.J., Smoothed particle hydrodynamics: theory and application to non-spherical stars, Monthly notices of the Royal Astronomical Society, 1977, 181(3), 375-389.

[4] KAFAJI I.K.A., Formulation of a dynamic material point method (MPM) for geomechanical problems, Doctoral dissertation, Institut für Geotechnik der Universität Stuttgart, 2013.

[5] WIĘCKOWSKI Z., The material point method in large strain engineering problems, Computer Methods in Applied Mechanics and Engineering, 2004, 193(39), 4417-4438.

[6] OÑate E., Idelsohn S.R., Del Pin F., Aubry R., The particle finite element method - an overview, International Journal of Computational Methods, 2004, 1(02), 267-307. DOI: $10.1142 / \mathrm{S} 0219876204000204$

[7] QIU G., Henke S., Grabe J., Applications of Coupled Eulerian-Lagrangian method to geotechnical problems with large deformations, Proceeding of SIMULIA customer conference, 2009, 420-435.

[8] PuCKer T., Grabe J., Numerical simulation of the installation process of full displacement piles, Computers and Geotechnics, 2012, 45, 93-106. DOI: 10.1016/ j.compgeo.2012.05.006.

[9] QIU G., Henke S., GraBe J., Applications of a Coupled Eulerian-Lagrangian approach on geomechanical problems involving large deformation, Computers and Geotechnics, 2011, 38(2011), 30-39. DOI: 10.1016/j.compgeo.2010.09.002.

[10] Robertson P.K., CABAL K.L., Cone Penetration Testing for Geotechnical Engineering, (4th ed.), Signal Hill, Greg Drilling \& Testing, Inc., 2010. 
[11] Marchetti S., Monaco P., Totani G., Calabrese M., The Flat Dilatometer Test (DMT) in Soil Investigations-A Report by the ISSMGE Committee TC16, Proc. Int. Conf. on in Situ Measurement of Soil Properties and Case Histories, Bali 2001, 95-131.

[12] Schanz T., Vermeer P.A., Angles of friction and dilatancy of sand, Géotechnique, 1996, 46(1), 145-152.

[13] Bolton M.D., The strength and dilatancy of sands, Geotechnique, 1986, 36(1), 65-78.

[14] Jamiolkowski M., Lo Presti D.C.F., Manassero M., Evaluation of relative density and shear strength of sands from CPT and DMT, [in:] Soil behavior and soft ground construction, 2003, 201-238, ASCE. DOI: 10.1061/40659(2003)7.
[15] Dassault Systèmes. (2013). Abaqus User Manual Version 6.13.

[16] Yu M.-H., Ma G.-W., QIANG H.-F., Zhang Y.-Q., Generalized Plasticity, Springer, Berlin, 2006, DOI: 10.1007/3-54030433-9.

[17] Tomlinson M., Woodward J., Pile design and Construction Practice, (5th ed.), Taylor \& Francis, New York 2008.

[18] Bustamante M., Gianeselli L., Pile bearing capacity prediction by means of static penetrometer $C P T$, Proceedings of the 2-nd European Symposium on Penetration Testing, May 1982, pp. 493-500.

[19] Kulhawy F.H., Limiting Tip and Side Resistance-Fact or Fallacy?, [in:] Foundation Engineering in the Face of Uncertainty: Honoring Fred H. Kulhawy, ASCE, 1984, 18-36. 